annual screening. Wide studies should be designed in order to evaluate the efficacy of re-screening.

References:

[1] He D, Bai F, Zhang $S$ et al. High incidence of tuberculosis infection in rheumatic diseases and impact for chemoprophylactic prevention of tuberculosis activation during biologics therapy. Clin Vaccine Immunol 2013; 20:842-847

[2] Carmona L, Gómez-Reino JJ, Rodríguez-Valverde V, et al. Effectiveness of recommendations to prevent reactivation of latent tuberculosis infection in patients treated with tumor necrosis factor antagonists. Arthritis Rheum 2005;52:1766-72

Disclosure of Interest: None declared

DOI: 10.1136/annrheumdis-2017-eular.6727

\section{AB0903 LABORATORY FINDINGS IN PATIENTS WITH CHIKUNGUNYA FEVER AND CHRONIC JOINT SYMPTOMS - A LONGITUDINAL ASSESSMENT}

A. Ranzolin ${ }^{1,2}$, R.M. Correia ${ }^{2}$, H.D. de Lima ${ }^{2}$, M.R.D.A. Freitas ${ }^{2}$, A.F.R. de Oliveira $^{2}$, A.L.B.P. Duarte ${ }^{1}$, C.D.L. Marques ${ }^{1}$, P.R.S. de Melo ${ }^{2}$, L.F. da Rocha $\mathrm{Jr}^{1,2} .{ }^{1}$ Hospital Das Clínicas of Pernambuco; ${ }^{2}$ Instituto de Medicina Integral Professor Fernando Figueira, Recife, Brazil

Background: Chikungunya Fever (CF) is an arbovirosis with a high attack rate, affecting large proportion of the population in its outbreaks $(85 \%>90 \%$ of infected are symptomatic). In general, it is recommended to carry out laboratory tests when patients reach subacute phase or show signs of severity at the beginning of the disease. There are few studies showing which laboratory results are relevant and their clinical applicability.

Objectives: To recognize the most frequent findings of laboratory tests in a cohort of patients with CF and chronic joint symptoms and to correlate laboratory results with clinical data.

Methods: Patients with diagnosis of CF (clinical and epidemiological criteria) were followed in a cohort study. Clinical data and laboratory tests were collected in a regular schedule in the first months of the disease.

Results: A total of 54 patients were enrolled during 10 months, persistent changes in some patients were recorded (table).

Table 1. Persistent laboratory findings in patients with Chikungunya Fever in subacute/chronic phases

\begin{tabular}{|c|c|}
\hline$>50 \%$ & Decreased vitamin D (53.8\%) \\
\hline $40 \%>50 \%$ & Increased CRP (43.3\%) \\
\hline $30 \%>40 \%$ & Decreased: HDL cholesterol (36.5\%), eosinophil (37.3\%), \\
\hline $20 \%>30 \%$ & $\begin{array}{l}\text { Increased: glucose }(28.3 \%) \text {, GGT }(27.4 \%), \gamma \text { globulin }(27.4 \%) \text {, glycated } \\
\text { hemoglobin }(26.4 \%) \text {, calcium (25.4\%), alkaline phosphatase }(24.5 \%), \beta \text { globulin } \\
(23.5 \%) \text {, cholesterol }(23.0 \%) \text { Decreased: total bilirubin }(20.0 \%)\end{array}$ \\
\hline $10 \%>20 \%$ & $\begin{array}{l}\text { Increased: triglycerides (17.6\%), LDH }(17.3 \%) \text {, ferritin (13.7\%), ALT (13.2\%), } \\
\text { direct bilirubin (12.0\%), a } 2 \text { globulin (11.7\%) Monocytosis (11.1\%), Limphocytosis } \\
(10.0 \%)\end{array}$ \\
\hline $5 \%>10 \%$ & $\begin{array}{l}\text { Hyperchloremia }(8.0 \%) \text { Increased: neutrophils }(7.54 \%) \text {, LDL }(5.88 \%) \text {, folic acid } \\
(5.88 \%) \text {, uric acid }(5.76 \%) \text {, platelets }(7.54 \%) \text { Decreased: CPK }(7.54 \%) \text {, albumin } \\
(5.88 \%) \text {, neutrophils }(9.43 \%) \text { Hyponatremia }(5.88 \%) \text {, }\end{array}$ \\
\hline
\end{tabular}

$\overline{C R P}=\mathrm{C}$ reactive protein, $\mathrm{GGT}=$ gamma glutamyl transferase, $\mathrm{LDH}=$ lactate dehydrogenase, $\mathrm{ALT}=$ alanine aminotransferase, $\mathrm{CPK}=$ creatine phosphokinase .

In the subacute phase, the ESR (erythrocyte sedimentation rate) correlated with number of swollen joints ( $r=0.45, p=0.03$ ), VAS (visual analogue scale) of pain $(r=0.72, p=0.0002)$, VAS patient's general health $(r=0.50 p=0.02)$, VAS by physician $(r=0.45, p=0.03)$ and with $\mathrm{HAQ}(r=0.51, p=0.01)$. In subacute phase the VAS of morning stiffness correlated with CRP $(r=0.46, p=0.02)$. In chronic phase, CRP correlated with VAS of pain $(r=0.47, p=0.02)$ and there was a reversal in the correlations between ESR and VAS of general health of the patient $(r=-0.54$, $p=0.03)$, VAS of physician $(r=-0.52, p=0.02)$, swollen joints $(r=-0.46 p=0.03)$ and $\mathrm{HAQ}(\mathrm{r}=-0.56, \mathrm{p}=0.01)$. ESR and SF-12 (mental component) were correlated $(r=0.61, p=0.01)$

Conclusions: Levels of ESR correlated with measures of pain and worsening of functional capacity in subacute phase. In chronic phase, there was reversal of this correlation, indicating that ESR does not reflect clinical worsening of patients at this stage. Further clinical studies are needed to better analize other alterations. References:

[1] Weaver SC, Lecuit M. Chikungunya virus and the global spread of a mosquito-borne disease. N Engl J Med 2015 Mar 26;372(13):1231-9.

[2] Brito CA, Sohsten AK, Leitão CC et al. Pharmacologic management of pain in patients with Chikungunya: a guideline. Rev Soc Bras Med Trop. 2016; 49(6):668-679.

Disclosure of Interest: None declared

DOI: 10.1136/annrheumdis-2017-eular.5599

\section{AB0904 FUSOBACTERIUM NECROPHORUM MASQUERADING AS NEISSERIA IN SEPTIC ARTHRITIS}

C.H. O'neill ${ }^{1}$, H. McCormick ${ }^{2}$, M. Leith ${ }^{1}$, L. McCorry ${ }^{3}$, J. McKenna ${ }^{2}$, A. Pendleton ${ }^{3}$, Y. Protaschik ${ }^{3}$, A. Loughrey ${ }^{2}$, P.V. Coyle ${ }^{2}$, D. Fairley ${ }^{2}$ ${ }^{1}$ Rheumatology; ${ }^{2}$ Microbiology; ${ }^{3}$ Belfast Health and Social Care Trust, Belfast, United Kingdom

Background: Infective arthritis with fusobacterium is rare and difficult to diagnose \& initially can be misidentified as Neisseria arthritis based on microscopy results. It is associated with Lemierre's Disease \& is important to recognise.

Objectives: To demonstrate that a "linked up" approach between culture and PCR in the analysis of joint fluids will provide timely identification of the organism and allow for appropriate antibiotic use \& to show the utility of bacterial 16S rRNA PCR in sterile site fluid analysis.

Methods: This is a case study of a pyogenic wrist infection with Fusobacterium necrophorum in the rheumatology department

Results: Our report follows a 17 year old caucasian female presenting with a history of left wrist pain, swelling and flu-like symptoms. Microscopy of joint aspirate revealed gram negative diplococci. Empirical antibiotic therapy, Ceftriaxone, was used to cover for potential gonococcus. Real-time PCR testing was negative for both gonococcus and meningococcus. However a real-time PCR assay targeting the bacterial $16 \mathrm{~S}$ ribosomal RNA gene detected bacterial DNA ${ }^{1}$. The patient did not clinically improve and further aspirate remained positive for the 16S rRNA gene target. As all joint aspirates and other specimens remained culture negative, the decision was taken to attempt bacterial 16S rRNA PCR and sequencing on DNA extracted directly from the joint aspirate. The sequences recovered were identified as $F$ necrophorum. This was eventually confirmed by anaerobic culture of the initial joint aspirate. A suspicion of Lemierre's disease (thrombophlebitis of the internal jugular vein and/or bacteraemia) was raised, however jugular venous dopplers were normal.

The outcome was favourable following guided antibiotic treatment.

Conclusions: This case illustrates that $F$. necrophorum infection may occur with unusual or disseminated presentation, but in the absence of the classical features of Lemierre's syndrome. The possibility of Neisseria was recognised early \& appropriate empirical antibiotic cover was used. This is important given the emergence of virulent meningococcal serogroup W ST11 strains causing infections with unusual presentation (including septic arthritis) in the UK². Reliance on microscopy findings alone could have led to an incorrect diagnosis of gonococcal septic arthritis - a condition with very low complication rates and excellent prognosis. In contrast, non-gonococcal septic arthritis is a medical emergency with significant morbidity and mortality ${ }^{3}$. The $F$. necrophorum infection in this case could have had fatal complications if it had been managed as a gonococcal infection. Secondly this case highlights the utility of bacterial 16S PCR and sequencing directly from a normally sterile site, allowing accurate diagnosis and appropriate treatment.

References:

[1] Yang S et al (2002)Quantitative Multiprobe PCR Assay for Simultaneous Detection and Identification to Species Level of Bacterial Pathogens J Clin Micro 40(9):3449-3454.

[2] Ladhani SN, et al(2014) Increase in Endemic Neisseria meningitidis Capsular Group W Sequence Type 11 Complex Associated With Severe Invasive Disease in England and Wales. Clinical Infectious Disease 60:578-585.

[3] Shirtliff \& Mader (2002) Acute septic arthritis. Clin Microbiol Rev. 15(4):527-44. Disclosure of Interest: None declared

DOI: 10.1136/annrheumdis-2017-eular.6272

\section{AB0905 THE EFFICACY OF TRIMETHOPRIM/SULFAMETHOXAZOLE TO PREVENT ACUTE-ONSET DIFFUSE INTERSTITIAL LUNG DISEASES WITH CONNECTIVE TISSUE DISEASE PATIENTS}

F.Y. Chen, K. Setoguchi, M. Ogawa, S. Kamei. Systemic Immunological Disease, Tokyo Metropolitan Komagome Hospital, Tokyo, Japan

Background: Acute-onset diffuse interstitial lung diseases (AoDILD) are highly mortal condition and their cause are often difficult to discriminate. Trimethoprim $80 \mathrm{mg} / \mathrm{sulfamethoxazole} 400 \mathrm{mg}$ single strength (TMP-SMX SS) has been used for Pneumocystis Pneumonia (PCP) prophylaxis and highly effective but the dose was originally developed in pediatric cancer patient's study and there is possibility that in connective tissue disease (CTD) patients, less dose can be as effective.

Objectives: The aim of this study is to examine hypothesis that taking TMP-SMX for PCP prophylaxis with CTD also have prophylactic effect against AoDILD and how about those effect in under dose patients for some reason

Methods: We retrospectively investigated data from 621 patients with TMP-SMX for PCP prophylaxis during and 43 patients who admitted for either acute respiratory failure/acute interstitial pneumonia/PCP/drug induced pneumonitis during 2004-2016 in our department.

Results: There was no single case who admitted to hospital due to AoDILD with TMP-SMX for PCP prophylaxis. There were 34 cases admitted for AoDILD and 9 cases (26\%) were dead. Among 25 cases, 5 cases developed AoDILD after TMP-SMX cessation. 70 cases ware taking under dose prophylaxis for some reasons but there was also no AoDILD case.

Conclusions: Taking TMP-SMX for PCP prophylaxis may also have prophylactic effect against AoDILD. And those effect may also exist even under dose. 